\title{
Tensile Fracture of an Iron and a Steel under Hydrostatic Pressures*
}

\section{By Masanobu OHMORI, ${ }^{* *}$ Masakazu INNO ${ }^{* * *}$ and Norio MATSUOKA ${ }^{* * * *}$}

\begin{abstract}
Synopsis
A commercial pure iron and a mild steel were tested in tension under hydrostatic pressure up to $3500 \mathrm{~kg} / \mathrm{cm}^{2}$ in order to find the cause of increase in tensile fracture ductility with pressure. The effects of initial density of dislocations and presence of initial voids on the pressure dependence of tensile ductility were also examined.

It was found that large ductility of specimen under hydrostatic pressure was brought only from retardation of initiation and growth of a kind of structural defects, i.e., voids, which could not be eliminated even after a full annealing. Although the annealed specimen with initial voids showed less ductility compared with the annealed one without the voids, the increase of fracture strain with pressure was larger for the former specimen. The specimen with higher density of dislocations had a smaller ductility than the specimen with the lower density, but the increase in fracture strain with pressure was found to be same for both specimens. The difference of fracture strain between the two specimens was nearly equal to the difference of void initiation strain defined as a strain at which voids of $0.1 \%$ in volume fraction occurred in the specimens. The process from the void initiation to fracture was, therefore, considered to be independent of the initial density of dislocations. Finally, it was found that the coalescence of voids, by which the final fracture was led, did not occur by sharp cracking but by internal necking and/or shearing of matrix between the voids.
\end{abstract}

\section{Introduction}

The present investigation is carried out to examine whether the increase in tensile ductility of the pure iron and steel deformed under high hydrostatic pressures is attributable only to the retardation in initiation and growth of structural defects such as voids or not. The effects of initial density of dislocations and of initial voids on the pressure dependence of ductility are also examined.

\section{Experimental Procedures}

The specimens were a commercial pure iron and a mild steel, the chemical analysis of which is tabulated in Table 1. The tensile specimen as shown in Fig. 1 was turned from forged round bars and followed by annealings in vacuum at $800^{\circ}$ and $920^{\circ} \mathrm{C}$ to obtain mean grain diameters of about 45 and $20 \mu \mathrm{m}$ for the pure iron and the mild steel, respectively. Compared

Table 1. Chemical composition of specimens (wt $\%$ )

\begin{tabular}{|c|c|c|c|c|c|c|c|}
\hline \multirow{2}{*}{ Specimen } & \multicolumn{7}{|c|}{ Element } \\
\hline & $\mathrm{C}$ & $\mathrm{Mn}$ & $\mathrm{Si}$ & $\mathrm{P}$ & $\mathrm{S}$ & $\mathrm{Ni}$ & $\mathrm{Cu}$ \\
\hline Pure iron & 0.015 & 0.15 & 0.20 & 0.008 & 0.011 & - & 0.04 \\
\hline Mild steel & 0.14 & 0.49 & 0.20 & 0.008 & 0.013 & 0.04 & - \\
\hline
\end{tabular}

with the non-metallic inclusions in the steel, those in the pure iron were larger in size and many of them were arranged along grain boundaries.

Details of the present experimental apparatus, in which various types of deformation can be given to the specimen under hydrostatic pressures up to $4000 \mathrm{~kg} / \mathrm{cm}^{2}$, have been reported in the previous paper. ${ }^{1)}$ Tensile deformations under pressures up to $3500 \mathrm{~kg} / \mathrm{cm}^{2}$ were given here at room temperature and at tensile speed of $2.8 \mathrm{~mm} / \mathrm{min}$.

\section{Experimental Results and Discussion}

\section{Variation of Ductility of Annealed Specimen with} Pressure

Nominal tensile stress-strain curves of the annealed pure iron and steel specimens under pressures of 1 and $3500 \mathrm{~kg} / \mathrm{cm}^{2}$ are illustrated in Fig. 2. Except that both yield and breaking points were somewhat lowered, the stress-strain relationship for a given

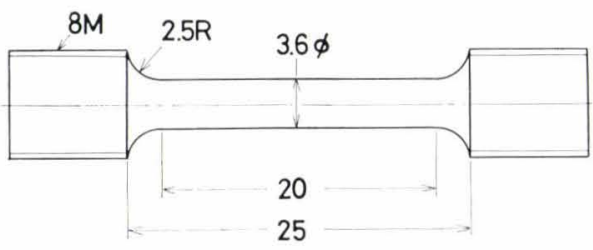

Fig. 1. Tensile specimen (dimension: $\mathrm{mm}$ )

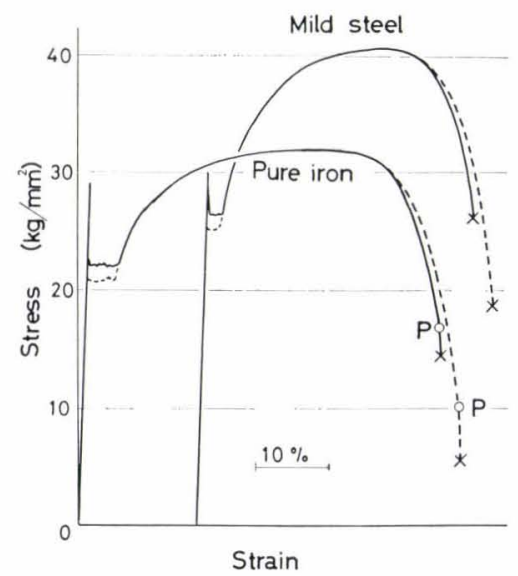

$P$ : points at which stress decreased rapidly

Fig. 2. Nominal tensile stress-strain curves obtained under pressures of $1 \mathrm{~kg} / \mathrm{cm}^{2}$ (solid lines) and $3500 \mathrm{~kg} / \mathrm{cm}^{2}$ (broken lines).

* $\quad$ Originally published in Journal of Japan Society for Technology of Plasticity, 18 (1977), 43, in Japanese. English version received June $15,1977$.

** Faculty of Engineering, Hiroshima University, Sendamachi, Hiroshima 730.

*** Formerly Graduate School, Hiroshima University. Now at Daikyo Co., Ltd., Hachihonmatsu, Higashi-hiroshima, 739-01.

**** Graduate School, Hiroshima University, Sendamachi, Hiroshima 730. 
material was not affected by hydrostatic pressure. A point $P$ at which the stress began to decrease rapidly appeared on a final stage of the curve obtained from the pure iron specimen and it was lowered with increasing pressure. Large cavities resulted from coalescence of voids were found, as shown in Photo. 1, in the necked region of the pure iron specimen unloaded after stretched slightly beyond the point $P$, but they were not found in the specimen stretched just before $P$. Therefore, as seen in copper specimens, ${ }^{2,3}$ ) it is concluded that $P$ is a point at which the large cavities begin to grow with coalescence of small voids. The reason why such a point as $P$ did not appear on the curve of the steel specimen should be explained from the fact that the final fracture occurred immediately after void coalescence.

The ductility defined as tensile fracture strain, $\varepsilon_{f}=\ln \left(A_{0} / A\right)$, is shown in Fig. 3 as a function of pressure, where $A_{0}$ is the original cross-sectional area of the specimen and $A$ the area after fracture. Both the ductility itself and the rate of increase of it to that of pressure $(p), d \varepsilon_{f} / d p$, were larger for the pure iron. The present observation that $d \varepsilon_{f} / d p=3.2 \times 10^{-4} \mathrm{~cm}^{2} / \mathrm{kg}$ for the pure iron is larger than $2.0 \times 10^{-4} \mathrm{~cm}^{2} / \mathrm{kg}$ for the steel agrees with the report that $d \varepsilon_{f} / d p$ becomes smaller with increasing tensile strength.

\section{Ductility of Specimens Prestrained under Different Pressures}

It is known that a ductile metal prestrained in tension under a high pressure and followed by stretching to fracture at $1 \mathrm{~kg} / \mathrm{cm}^{2}$ shows a larger total fracture strain than that for the one stretched at $1 \mathrm{~kg} / \mathrm{cm}^{2}$ from beginning to fracture. As reported previous$\mathrm{ly}{ }^{2,5)}$ this phenomenon implies that when each of the specimens taken from an identical material undergoes a given macroscopic plastic strain under different pressures, there arises a certain change in their ductility properties, i.e., their internal structures. Since a difference of ductility between the specimens stretched under pressures of 1 and $3500 \mathrm{~kg} / \mathrm{cm}^{2}$ should be a reflection of the above-mentioned difference of internal structures, the disclosure of this difference between the structures leads us to the essential under- standing of the cause of increase in ductility of the specimen subjected to the deformation under high pressure. There is shown in Fig. 4 the relationship

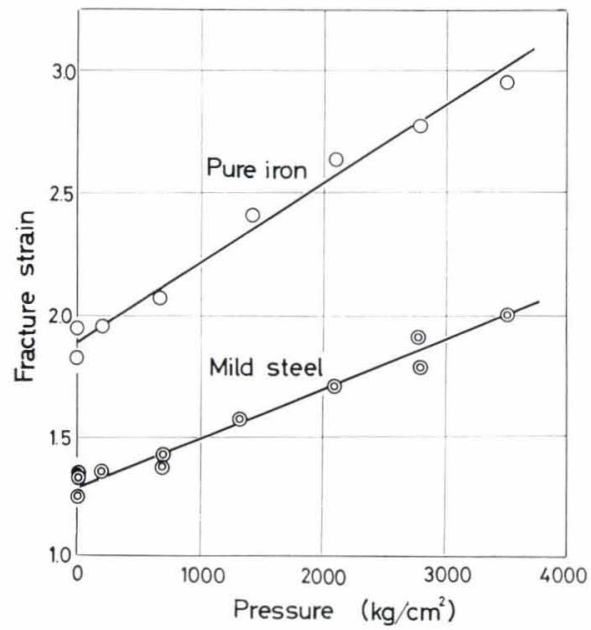

Fig. 3. Tensile fracture strain as a function of pressure



Broken lines with $\left(\varepsilon_{f}\right)_{1}$ : fracture strain of specimen prestrained at $1 \mathrm{~kg} / \mathrm{cm}^{2}$ Solid line with $\left(\varepsilon_{f}\right)_{3500}$ : under $3500 \mathrm{~kg} / \mathrm{cm}^{2}$

Fig. 4. Effect of prestrain on total fracture strain of specimens stretched to fracture at $1 \mathrm{~kg} / \mathrm{cm}^{2}$ subsequently to tensile prestraining under pressures of 1 and $3500 \mathrm{~kg} / \mathrm{cm}^{2}$

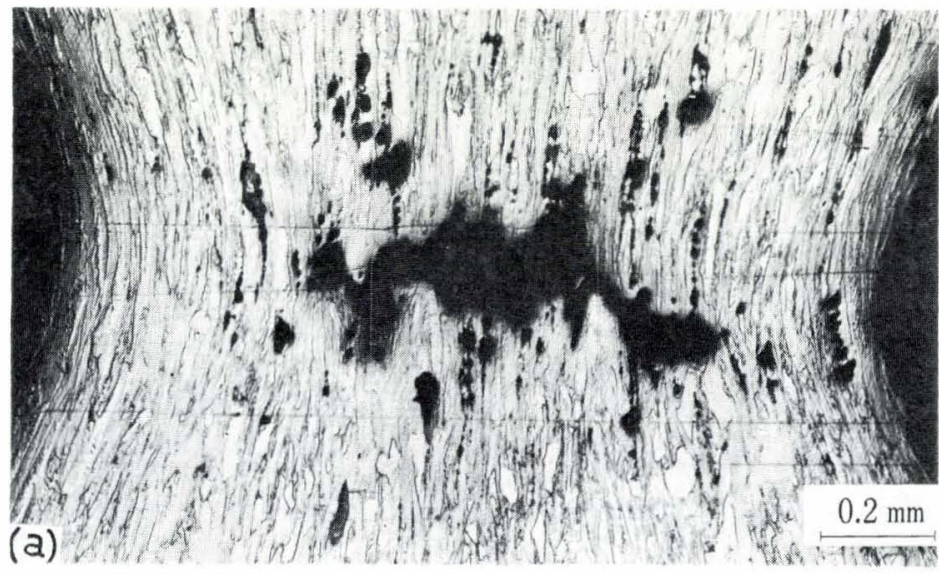

(a) stretched at $1 \mathrm{~kg} / \mathrm{cm}^{2}$

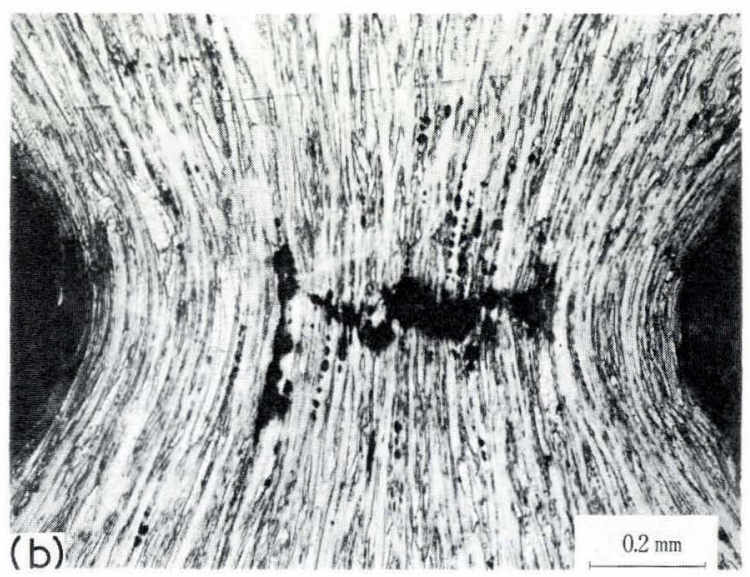

(b) under $3500 \mathrm{~kg} / \mathrm{cm}^{2}$

Photo. 1. Large cavities generated in necked region of pure iron specimen 
between total fracture strain and amount of prestrain for the specimens stretched to fracture at $1 \mathrm{~kg} / \mathrm{cm}^{2}$ after prestrain under pressures of 1 and $3500 \mathrm{~kg} / \mathrm{cm}^{2}$. The fracture strain of the specimen prestrained under $3500 \mathrm{~kg} / \mathrm{cm}^{2}$ began to increase beyond the prestrains of about 0.50 and 0.35 for the pure iron and the steel, respectively.

In order to examine the difference of fracture strain between the specimens annealed subsequently to the prestraining under different pressures and those asprestrained, the pure iron and mild steel specimens annealed in vacuum at $850^{\circ} \mathrm{C}$ after prestrain under pressures of 1 and $3500 \mathrm{~kg} / \mathrm{cm}^{2}$ were stretched to fracture at $1 \mathrm{~kg} / \mathrm{cm}^{2}$. The results of the above examination are given in Fig. 5. The fracture strain in this illustration represents sum of the prestrain and the additional strain given to the specimen stretched to fracture after annealing. The difference of fracture strain between the specimens prestrained under 1 and $3500 \mathrm{~kg} / \mathrm{cm}^{2}$ began to appear beyond the prestrain of about 0.50 for the pure iron and of about 0.35 for the mild steel and increased with prestrain in the same manner as shown in Fig. 4 for the specimens prestrained but not annealed. It is deduced, therefore, that the difference of fracture strain between the specimens subjected to the same amount of prestrain but under different pressures does not come from the change in the amount of microscopic structural defects such as dislocations but from the change in the amount of defects such as voids which can not be eliminated by annealing. The above results tell us also that the larger ductility of the specimen deformed under the higher pressure is attributable only to the retardation of initiation and growth of voids.

\section{Variation of Ductility of Specimen Containing Voids with Pressure}

At a given tensile strain, a larger volume fraction of voids can be introduced in the specimen stretched at a blue-brittleness temperature than in the specimen stretched at room temperature. About $1 \%$ of volume fraction of voids was generated in the necked region of the iron and steel specimens by giving necking true strain of 0.73 to the former at $200^{\circ} \mathrm{C}$ and 0.65 to the latter at $250^{\circ} \mathrm{C}$. Examples of the introduced voids are shown in Photo. 2. The tensile ductility was examined as shown in Fig. 6 as a function of pressure for the specimen not annealed and the specimen annealed at $850^{\circ} \mathrm{C}$ after the voids had been generated. The ductility of the annealed specimen without initial voids is also shown in this illustration with broken lines to compare with the present results. It should be noted that the strain given at the bluebrittleness temperature to introduce the voids is not included in the present fracture strain. The increasing rate of fracture strain with pressure, $d \varepsilon_{f} / d p$, for the iron and steel specimens annealed subsequently to void generation was $3.7 \times 10^{-4}$ and $2.9 \times 10^{-4} \mathrm{~cm}^{2} / \mathrm{kg}$, respectively. These values are larger than those of the specimens without initial voids $\left(3.2 \times 10^{-4}\right.$ and

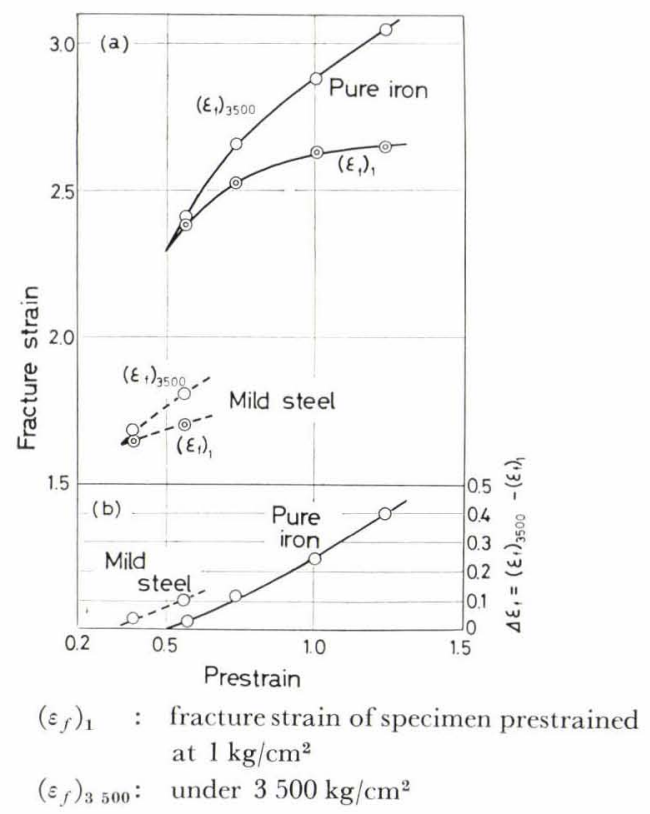

Fig. 5 (a). Effect of prestrain on total fracture strain of specimens stretched to fracture at $1 \mathrm{~kg} / \mathrm{cm}^{2}$ after they were prestrained under different pressures and followed by annealing at $850^{\circ} \mathrm{C}$

(b). Variation of $\Delta \varepsilon_{f}=\left(\varepsilon_{f}\right)_{3500}-\left(\varepsilon_{f}\right)_{1}$ with prestrain

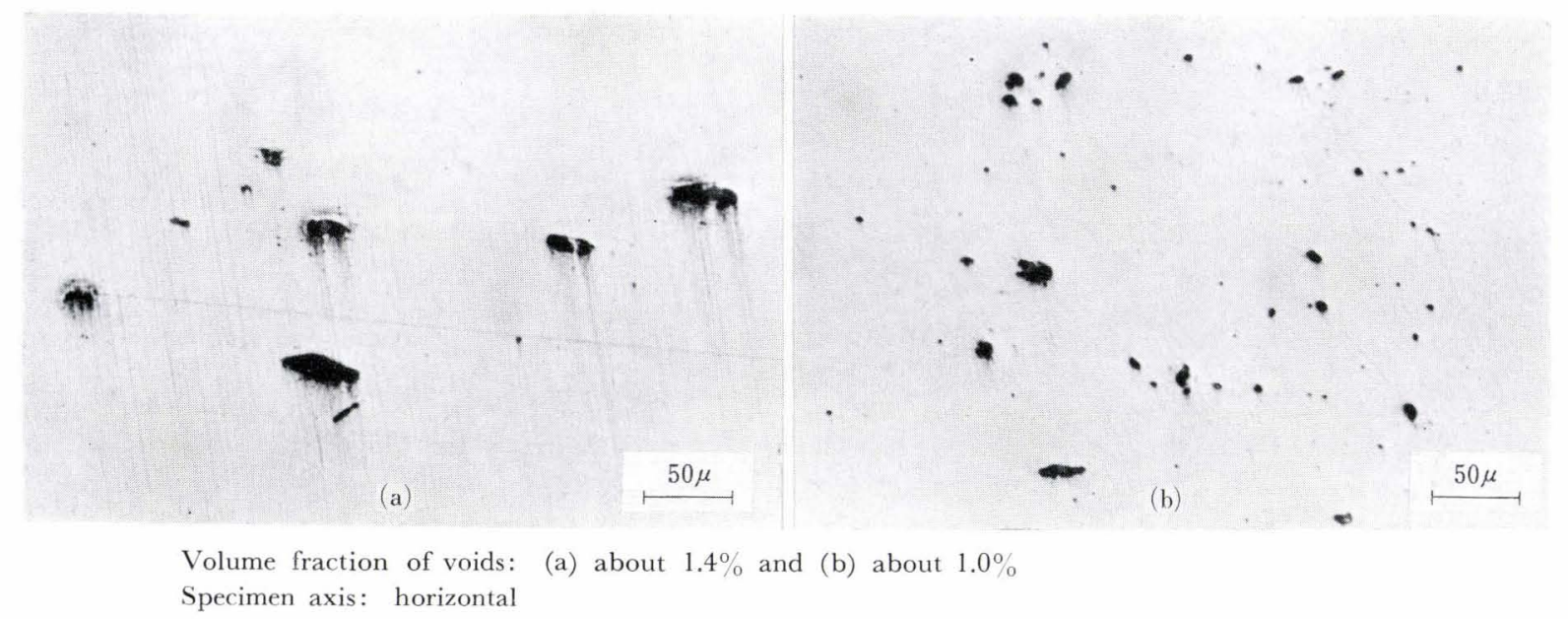

Photo. 2. Voids generated in pure iron (a) and mild steel (b) by stretching them at blue-brittleness temperatures. 
$2.0 \times 10^{-4} \mathrm{~cm}^{2} / \mathrm{kg}$ for the iron and the steel, respectively). A similar phenomenon has also been observed in a 70-30 brass $^{6)}$ and a sintered copper. ${ }^{7}$ )

The ductility measured in the tensile deformation at $1 \mathrm{~kg} / \mathrm{cm}^{2}$ was smaller for the annealed specimen with initial voids than for that without the voids, since the growth and coalescence of voids occurred at an earlier stage of deformation in the former specimen. The pressure reduces the hydrostatic stress component in the specimen so as to restrain the growth and coalescence of voids. As can be understood from the distribution of triaxial stresses in the necked region of the specimen, the restraining effect appears more remarkably in a region closer to the periphery of the specimen, and the region in which the restraining effect occurs gets towards the center of the specimen with increasing pressure. In fact, when a longitudinal section of the specimen fractured at $1 \mathrm{~kg} / \mathrm{cm}^{2}$ was examined, it was found that the volume fraction of voids in the central region slightly below the fracture surface was independent of the presence of initial voids but the fraction of voids in the periphery was larger in the specimen with the initial voids than in the specimen without them. On the contrary, the growth of voids just below the fracture surface of specimen stretched under $3500 \mathrm{~kg} / \mathrm{cm}^{2}$ scarcely depended on the presence of initial voids not only in the central region but also in the periphery. From the above evidences, it is concluded that the growing behaviour of voids in the necked region of the annealed specimen with initial voids approaches the behaviour of voids produced freshly in the specimen with increasing pressure. Namely, the difference of fracture strain between the annealed specimens with and without initial voids is reduced with pressure, and this difference is thought to be eliminated under a pressure much higher than that achieved in the present experiment. A larger value in $d \varepsilon_{f} / d p$ for the

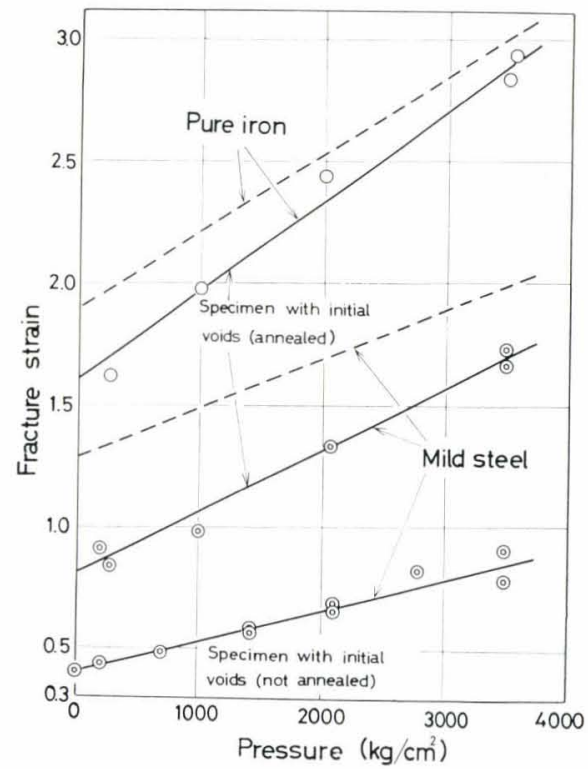

Fig. 6. Effect of pressure on fracture strain of specimens having initial voids. Broken lines are reproduced from Fig. 3 for annealed specimens without initial voids. annealed specimen with initial voids can thus be explained. The fact that $d \varepsilon_{f} / d p$ of an annealed 70 30 brass grows with increasing initial voids can also be explained in the same manner. ${ }^{6}$ )

As seen in Fig. 6, both $\varepsilon_{f}$ and $d \varepsilon_{f} / d p$ of the mild steel specimen not annealed after the voids were generated are much smaller than those of the annealed specimen with initial voids.

\section{Variation of Ductility of Specimens Having Different Initial Dislocation Density with Pressure}

The effect of dislocation density on the pressure dependence of ductility has not been known to present days. Keh et al. ${ }^{8)}$ carried out a tension test with an annealed $0.035 \%$ carbon steel at $25^{\circ}, 200^{\circ}$ and $250^{\circ} \mathrm{C}$ to formulate a relationship between the dislocation density and given strain, and they found that the density was actually equal in both specimens deformed at $200^{\circ}$ and $250^{\circ} \mathrm{C}$ but it was several times as large as the density in the specimen deformed at $25^{\circ} \mathrm{C}$. For example, the dislocation density at the shear strain of 0.16 was about $1.0 \times 10^{8} / \mathrm{cm}^{2}$ in the specimen deformed at $25^{\circ} \mathrm{C}$ and about $2.5 \times 10^{8} / \mathrm{cm}^{2}$ in both specimens stretched at $200^{\circ}$ and $250^{\circ} \mathrm{C}$. In the present experiment, the specimen with higher dislocation density was prepared by giving the tensile strain of 0.08 at $200^{\circ} \mathrm{C}$ to the annealed pure iron and at $250^{\circ} \mathrm{C}$ to the annealed mild steel. On the other hand, the same tensile strain was given at room temperature to the pure iron and the mild steel to provide the specimen with a lower dislocation density. Tensile stress-strain curves recorded at $1 \mathrm{~kg} / \mathrm{cm}^{2}$ and room temperature are illustrated in Fig. 7 for the specimens of the different dislocation densities. The calculation of stress and strain is based on the crosssectional area reduced and the gauge length extended by giving the strain of 0.08 . These curves show that the specimens with the higher dislocation density are

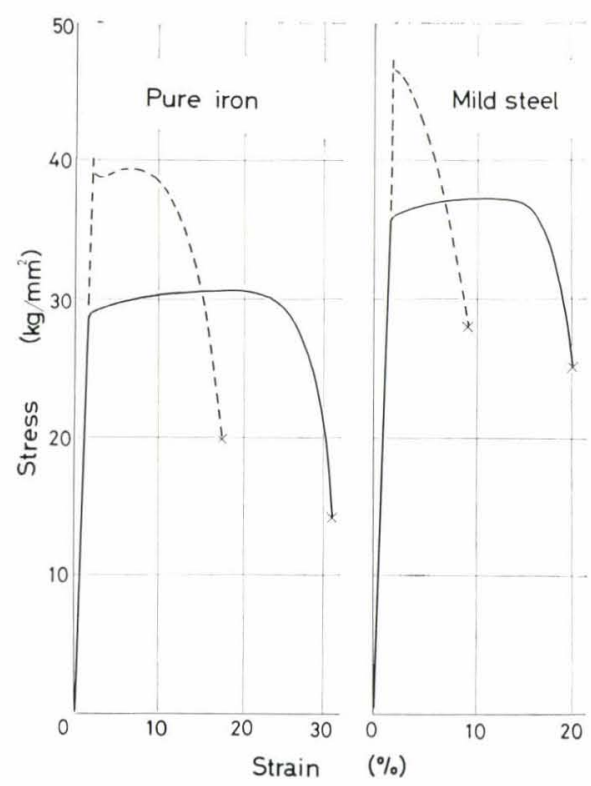

Fig. 7. Nominal tensile stress-strain curves obtained at room temperature for the specimen with lower dislocation density (solid lines) and that with higher density (broken lines) 
less ductile, though they have a higher yield strength.

The pressure dependences of ductility for the specimens with different dislocation densities are shown in Fig. 8 with solid lines. The prestrain of 0.08 is not included in the present fracture strain. In both cases of the pure iron and the mild steel, the ductilitypressure relationship of the specimen with the lower density almost coincides with that of the annealed specimen shown in Fig. 3. The fracture strain was smaller for the specimen with the higher dislocation density, though the value of $d \varepsilon_{f} / d p$ was independent of the density in contrast to the phenomenon that $d \varepsilon_{f} / d p$ of the annealed specimen depended on the volume fraction of initial voids. This means that the difference of fracture strain between the specimens with the lower and higher dislocation densities remains constant irrespective of pressure. The fact that $d \varepsilon_{f} / d p$ is independent of the dislocation density is contradictory to the finding ${ }^{4)}$ that $d \varepsilon_{f} / d p$ decreases with increasing tensile strength, since the strength is much affected by the density.

\section{Effects of Dislocation Density and Pressure on Void Initiation Strain}

According to a detailed observation ${ }^{9)}$ on the surface of a steel sheet specimen subjected to the tensile deformation, a few defects, i.e., cracking of a cementite particle and separation of an interface between inclusions and matrix, occur even at a small strain of 0.05 . Since the start of void initiation is thus difficult to determine strictly, the strain at which voids of $0.1 \%$ in volume fraction originate has been defined here as a void initiation strain $\left(\varepsilon_{i}\right)$. The pressure dependence of $\varepsilon_{i}$ is shown in Fig. 8 with broken lines for the specimens with the lower and higher density of dis-

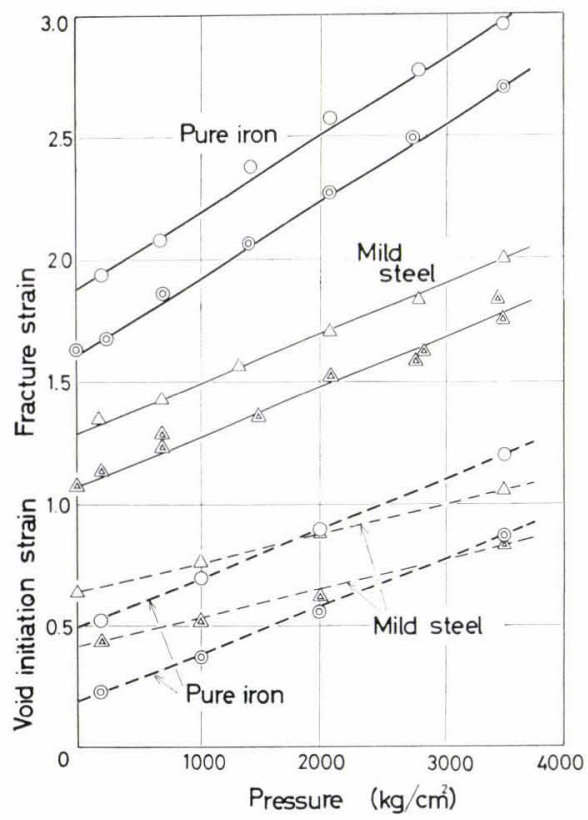

$0, \Delta:$ results of specimens with lower dislocation density

(C), $\Delta$ : with higher dislocation density

Fig. 8. Variations of fracture strain (solid lines) and void initiation strain (broken lines) with pressure locations. The prestrain of 0.08 given at room temperature or a blue-brittleness temperature to make preparation of the specimens with different dislocation densities is not included in the present void initiation strain. In both cases of the pure iron and the mild steel, $\varepsilon_{i}$ of the specimen with the higher dislocation density was smaller but increased linearly with pressure, being parallel to that of the specimen with the lower density. The difference of $\varepsilon_{i}$ between the specimens with the lower and higher dislocation densities is about 0.30 for the pure iron and about 0.24 for the steel under pressures encountered in the present experiment. The increasing rate of $\varepsilon_{i}, d \varepsilon_{i} / d p$ as well as $d \varepsilon_{f} / d p$ with pressure, is larger for the pure iron compared with the steel. $d \varepsilon_{i} / d p$ was about $2.0 \times 10^{-4}$ and $1.2 \times 10^{-4} \mathrm{~cm}^{2} / \mathrm{kg}$ for the iron and the steel specimens, respectively.

The difference of $\varepsilon_{f}$ between the specimens with the lower and higher dislocation densities was independent of pressure and it was about 0.30 for the pure iron and about 0.22 for the steel as shown in Fig. 8. Since the above difference of $\varepsilon_{f}$ is equal to that of $\varepsilon_{i}$ between both specimens for a given material, it can be said that the decrease of ductility with increase in dislocation density is brought about only by the decrease of $\varepsilon_{i}$. The fact that $\varepsilon_{f}-\varepsilon_{i}$ under a given pressure is independent of the initial dislocation density suggests that the process from void initiation to fracture is not influenced by the density of dislocations.

The ratio of void initiation strain to fracture strain, $\varepsilon_{i} / \varepsilon_{f}$, is presented in Fig. 9 against pressure. The ratio increased with pressure and it was larger at a given pressure in the mild steel than in the pure iron. And for a given material, the ratio was larger for the specimen with the lower initial density of dislocations. If it is assumed that $\varepsilon_{i}$ and $\varepsilon_{f}$ shown in Fig. 8 can be extrapolated linearly beyond the pressure covered in the present experiment, $\varepsilon_{i} / \varepsilon_{f}$ of the pure iron stretched under pressure of $10000 \mathrm{~kg} / \mathrm{cm}^{2}$ will be about $49 \%$ for the specimen with the lower dislocation density and about $46 \%$ for that with the higher density, while $\varepsilon_{i} / \varepsilon_{f}$ of the steel stretched under the same pressure will be about 56 and $52 \%$ for the specimens with the lower and higher density, respectively. Thus, $\varepsilon_{i} / \varepsilon_{f}$

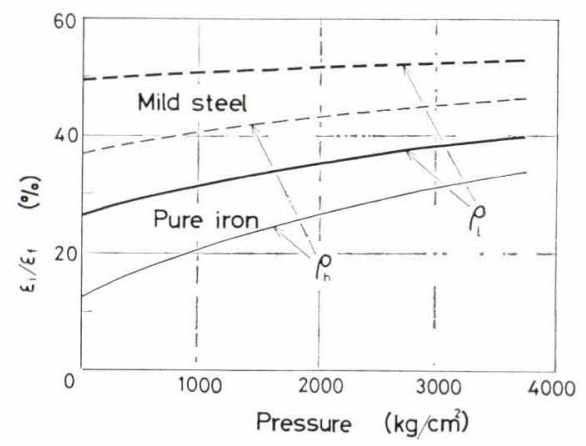

$\rho_{l}, \rho_{h}$ : lower and higher dislocation densities, respectively

Fig. 9. Variation of ratio of void initiation strain $\left(\varepsilon_{i}\right)$ to fracture strain $\left(\varepsilon_{f}\right)$ with pressure 
under a very high pressure seems to become independent of the materials used here and of the initial dislocation density. In respect that a large value of $\varepsilon_{i} / \varepsilon_{f}$ is favourable in addition to the main requirement of a large value of $\varepsilon_{f}$ to obtain good and sound products in the deformation processing, the high pressure is said to be of great advantage to the plastic working operations of metals.

\section{Processes of Ductile Fracture}

The fracture process of the annealed specimen was examined here. In the case of the pure iron, interfaces between large inclusions and matrices were separated in the direction normal to the tensile axis at an early stage of deformation to grow into relatively large voids, and small voids were also produced around fine inclusions arranged along grain boundaries. While most of the large voids were prolonged along the tensile axis without their coalescences even at a stage of considerably large deformation, the small voids along the boundaries were developed with the internal necking of matrix between the adjacent voids. The above mentioned features are shown in Photo. 3, which is a longitudinal section of the specimen stretched at $1 \mathrm{~kg} / \mathrm{cm}^{2}$ up to the strain of 1.30 . On the other hand, voids in the mild steel specimen were originated from the crackings in the pearlite colonies as well as the separations of inclusion-matrix interfaces. The originated voids grew with deformation, remaining almost unchanged in their equi-axed shape. Coalescences of the voids at a very large strain occurred with the internal necking and/or shearing of matrices between the voids in both cases of the pure iron and mild steel specimens.

Although it has been reported by some investigators $^{10)}$ that the voids are linked together by sharp cracks, Onodera et al. ${ }^{11)}$ have recently contended against this mechanism of void coalescence. A longitudinal section of the pure iron specimen stretched near to fracture under $3500 \mathrm{~kg} / \mathrm{cm}^{2}$ is shown in Photo. 4. The voids frequently seemed to be linked together by the sharp cracks as seen in Photo. 4 (a), but the crack-like defects were changed always into cavities as shown in Photo. 4 (b) by a very light polishing on the felted clo'h. The above observations show that the coalescence mechanism of voids due to sharp

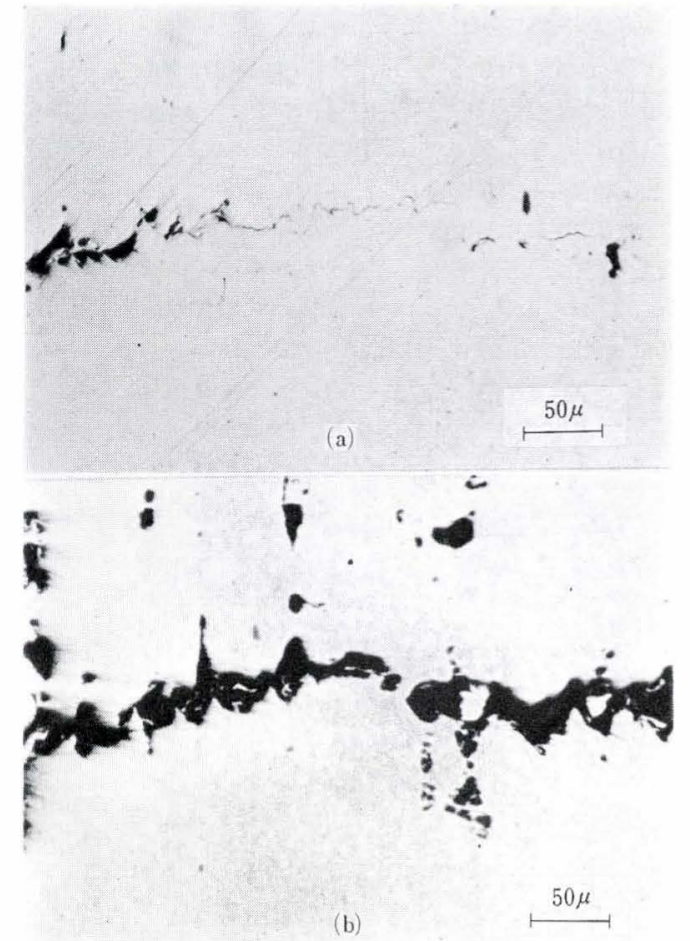

Photo. 4. Longitudinal section in necked region of pure iron specimen stretched near to fracture under $3500 \mathrm{~kg} /$ $\mathrm{cm}^{2}$. Tensile axis is vertical. Sharp crack-like defects (a) observed after comparatively heavy polishing on felted cloth are eliminated and changed to cavities (b) by very light polishing on the cloth.

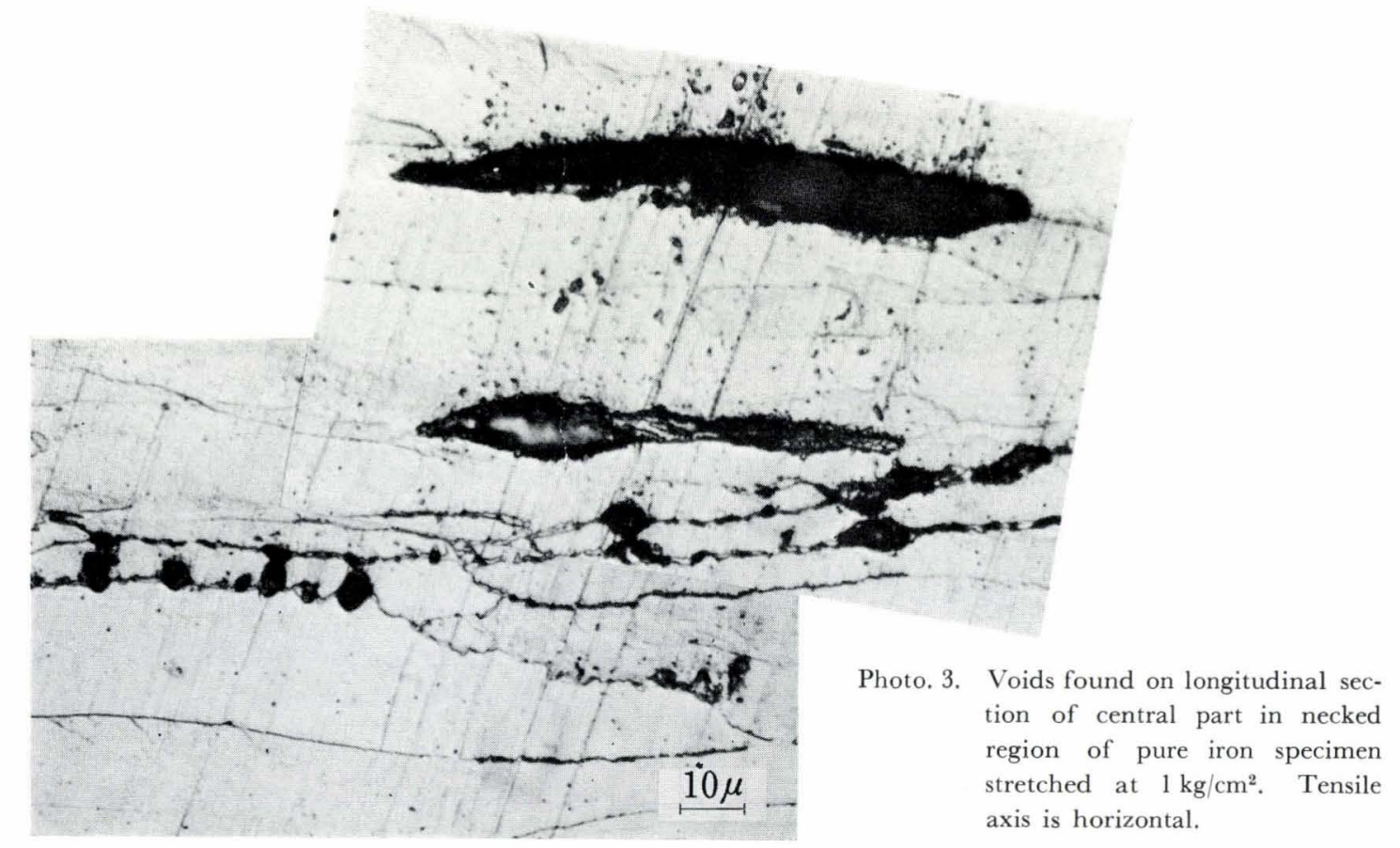


cracks would not be true, since the cavities can be covered with a thin film of plastically deformed matrix in a certain polishing condition as pointed out by Onodera and Teshima. ${ }^{11}$ )

\section{Conclusions}

The following results were obtained from the tensile tests of a commercial pure iron and a mild steel specimens under hydrostatic pressures up to $3500 \mathrm{~kg} / \mathrm{cm}^{2}$.

(1) When the annealed specimen of a given material was stretched to fracture at $1 \mathrm{~kg} / \mathrm{cm}^{2}$ subsequently to the tensile prestrainings under pressure of 1 and $3500 \mathrm{~kg} / \mathrm{cm}^{2}$, the fracture strain of the specimen prestrained under the higher pressure began to be larger beyond a certain prestrain and the difference of fracture strain between the specimens prestrained under the above pressures increased with prestrain.

(2) The difference of fracture strain between the specimens fully annealed after prestrain in tension under pressures of 1 and $3500 \mathrm{~kg} / \mathrm{cm}^{2}$ also varied with increasing prestrain in the same manner as observed in the specimens not annealed after prestraining. The result given above (1) is, therefore, concluded to be attributable to the fact that the volume fraction of structural defects such as voids, which could not be eliminated even by full annealing, was smaller in the specimen prestrained under the higher pressure. The fact that the specimen under the higher pressure revealed the larger fracture ductility should be explained in terms of the retardation of initiation and/or growth of the voids.

(3) Although the annealed specimen with initial voids showed less ductility compared with the annealed one without the voids, the fracture strain increased more rapidly with pressure for the former specimen.

(4) The specimen with a higher density of dislocations had a smaller ductility than the specimen with a lower density, but the fracture strain increased at the same rate with increasing pressure for both the specimens.

(5) The difference of fracture strain between the specimens having different dislocation densities was nearly equal to the difference of void initiation strain defined as a strain at which voids of $0.1 \%$ in volume fraction occurred in the specimens. This finding and the result given in (4) suggest that the process from the void initiation to fracture under a given pressure is independent of the initial dislocation density.

(6) The coalescence of voids, by which the final fracture was led, did not occur by sharp cracking but by internal necking and/or shearing of matrix between the voids.

\section{Acknowledgements}

The present authors would like to express their thanks to Messers. A. Sakamoto and K. Maeura for their cooperation in the present experiment.

\section{REFERENCES}

1) M. Ohmori, Y. Yoshinaga, T. Kawahata and Y. Sanemasu: J. Japan Inst. Metals, 33 (1969), 509.

2) M. Ohmori, M. Arikawa and M. Inno: J. Japan Soc. Tech. Plasticity, 18 (1977), 22.

3) K. Showaki: J. Japan Soc. Tech. Plasticity, 14 (1973), 885.

4) M. Yajima, M. Ishii and M. Kobayashi: J. Japan Soc. Tech. Plasticity, 9 (1968), 847.

5) M. Ohmori, Y. Yoshinaga, K. Sukegawa and Y. Maruyama: J. Soc. Mat. Science, Japan, 20 (1971), 937.

6) M. Ohmori, A. Himoto and Y. Sakakibara: J. Japan Soc. Tech. Plasticity, 15 (1974), 760.

7) K. Ohji, K. Ogura and Y. Mutoh: Trans. Japan Soc. Mech. Eng., 42 (1976), 31.

8) A. S. Keh, Y. Nakada and W. C. Leslie: Dislocation Dynamics, ed. by A. R. Rosenfield, G. T. Hahn, A. L. Bement, Jr. and R. I. Jaffe, McGraw-Hill, New York, (1968), 381.

9) K. Matsuto and K. Ohsawa: Private communication.

10) D. P. Clausing: Trans. ASM, 60 (1967), 504.

11) R. Onodera and S. Teshima: J. Japan Inst. Metals, 39 (1975), 648 . 